\title{
UNA PROPUESTA POSMODERNISTA DE CONCILIAR LAS OPERACIONES DE PAZ DE LA ONU CON LA DIGNIDAD HUMANA
}

\author{
Krystian COMPLAK*
}

RESUMEN: El autor contesta la pregunta sobre si las operaciones de paz de la ONU pueden ser llevadas a cabo sin vulnerar la dignidad humana. Luego de analizar la índole de las acciones pacifistas onusienses, se contempla la calidad inalterable de la dignidad humana en contraste con las llamadas causas eximentes penales. El autor concluye que el esquema de la preservación 'manu militari' del orden público internacional - introducido hace más de medio siglo - ya no se ajusta a la nueva etapa de la tutela de los derechos humanos, cuya punta de lanza es la dignidad de la persona humana. En adición a esto, al orden internacional, desde hace tiempo, está prohibido el recurso a la responsabilidad colectiva. Sin embargo, la dignidad del ser humano - como norma superior absoluta de cumplimiento incondicional - sigue siendo desplazada en la práctica judicial por otras normativas de rango inferior.

ABSTRACT: The author answers the question wether UN peace-keeping operations can be conducted without infringing the dignity of man. After studying this kind of peaceful actions by the United Nations, he examines the non-derogable character of human dignity in the face of the so-called defences. The author concludes that the model of maintaining by force international public order - established more than a half-century ago- has not yet been adapted to new stage of human rights protection, having as its edge the dignity of the human being. Furthermore, the recourse to collective responsibility has been forbidden in international public law for a long time. However, the dignity of the human person - as a supreme and absolute norm of unconditional fulfillment-continues to be displaced, in judiciary practice, by other rules of lower category.

RÉSUMÉ: L'auteur aborde la question de savoir si les opérations de paix de l'ONU peuvent être réalisées sans la violation de la dignité de la personne humaine. Après avoir examiné la nature des actions pacifistes onusiennes, il étudie l'intangibilité de la dignité de l'être humaine par rapport a ce qu'on appelle dans le droit pénal les circonstances absolutoires. L'auteur conclu que le mécanisme pour faire assurer, manu militar, l'ordre public international -institue il y a plus d'un demi-siècle-n'est plus conforme au niveau actuel de la protection des droits d'homme, ayant pour but principale la défense de la dignité humaine. En plus, la communauté internationale, s'est demis depuis longtemps, de l'usage de la responsabilité collective. Pourtant, la dignité de l'être humaine - en tant que norme suprême applicable sans exceptions-est substitue dans la jurisprudence aux règles de bas rang.

* Catedrático de derecho constitucional en la Universidad de Wroclaw, Polonia. 
SUMARIO: I. Índole militar de las operaciones de paz. II. Absoluta defensa de los 'derechos de la dignidad humana'. III. Circunstancias eximentes de los ordenamientos jurídicos internos.

IV. Conclusiones.

A primera vista, el examen del tema señalado puede despertar reservas. Muchas personas expresan su aprobación o incluso admiración para las acciones de los llamados cascos azules de la Organización de las Naciones Unidas. Éstos han encontrado tan grande respeto que se les concedió el Premio Nobel de la Paz en 1998. Aun más, a las operaciones de paz se las presenta a veces como si se efectuaran en nombre o conforme la dignidad del hombre.

El objetivo del artículo es inquirir si se pueden compaginar las operaciones de paz de la ONU con la dignidad de los soldados que participan en ellas. Luego de presentar la naturaleza de las operaciones de paz de las Naciones Unidas (I), contemplo la protección absoluta de los derechos inherentes a la dignidad humana en el derecho internacional y a través de los órganos judiciales (II), para terminar con la indicación de las bases jurídicas que excluyen la responsabilidad, en caso de vulnerar la dignidad de la persona humana (III).

\section{I. ÍNDOLE MILITAR DE LAS OPERACIONES DE PAZ}

La posibilidad de realizar, por las fuerzas de paz de la ONU, acciones militares, nunca suscitaba dudas. ${ }^{1}$ El artículo 42 de la Carta de la ONU estatuye que:

Si el Consejo de Seguridad estimare que las medidas de que trata el artículo 41 pueden ser inadecuadas o han demostrado serlo, podrá ejercer, por medio de fuerzas aéreas, navales o terrestres, la acción que sea necesaria para mantener o restablecer la paz y la seguridad internacionales. Tal acción podrá comprender demostraciones, bloqueos y otras operaciones ejecutadas por fuerzas aéreas, navales o terrestres de Miembros de las Naciones Unidas.

1 Compárense el punto pertinente en la obra de Conforti, B., The Law and Practice of the United Nations, London-Boston, The Hague, 2000, pp. 194 y ss.; y la monografía sobre le tema de Emanuelli, B., Les Actions militaires de l'ONU et droit international humanitaire, Montreal, 1995. 
El Consejo de Seguridad puede resolver asimismo sobre el uso de la fuerza en los límites de un Estado al intervenir en la guerra civil, cuando es de opinión que la situación interna de un país dado constituye una amenaza para la paz. El carácter 'doméstico' no es un óbice para las restricciones establecidas en el artículo 7 al 2 de la Carta de la ONU. Se puede hasta demostrar que el Consejo de Seguridad en las condiciones de crisis nacionales se inmiscuye la mayor de las veces en los denominados asuntos internos de los Estados. El empleo de las medidas castrenses por el Consejo de Seguridad es una acción internacional para mantener el orden. En estos casos, el Consejo de Seguridad actúa directamente y no por medio de mandamiento o recomendaciones dirigidos a los Estados. Esto consiste en el aprovechamiento de las tropas nacionales bajo el mando internacional subordinado al Consejo de Seguridad.

Para llevar a cabo la acción castrense en cuestión, el Consejo de Seguridad tiene el deber de concluir las acuerdos especiales con los Estados miembros. ${ }^{2}$ Basándose en ellos, los integrantes de la ONU ponen a disposición del Consejo de Seguridad las fuerzas armadas, la ayuda y las facilidades, incuso el derecho de paso, que sean necesarias para el propósito de mantener la paz y la seguridad internacionales. Dichos convenios fijan el número y clase de las fuerzas armadas, su grado de preparación, como también la naturaleza de las facilidades y de la ayuda que habrán de darse. Además, para que la ONU pueda "tomar medidas militares urgentes, sus miembros mantendrán contingentes de fuerzas aéreas nacionales inmediatamente disponibles para la ejecución combinada de una acción coercitiva internacional". Se establecerá también un Comité de Estado Mayor para asegurar y asistir al Consejo de Seguridad en todas las cuestiones relativas a sus necesidades militares para el mantenimiento de la paz y la seguridad internacionales, el empleo y comando de las fuerzas puestas a la disposición de este órgano, a la regulación de los armamentos y al posible desarme.

El Consejo de Seguridad nunca concluyó los acuerdos sobre los contingentes. ${ }^{3}$ Jamás funcionó un Comité de Estado Mayor. Las acciones

2 En cuanto a los documentos internacionales, citados en este artículo, la mayoría de las veces eran los compilados por Bautista Rivanola Paoli, J., Instrumentos internacionales fundamentales, Asunción, 1999.

3 Compárense Czaplinski, W. y Wyrozumska, A., Prawo miêdzynarodowe publiczne. Zagadnienia systemowe [El derecho público internacional. Cuestiones de sistema], Varsovia, 1999, pp. 518, passim. 
electivas emprendidas hasta ahora por la ONU eran contrarias a las disposiciones de su carta o salían fuera de estas disposiciones. En el pasado, hubo una fuerte tendencia para transferir las atribuciones del Consejo de Seguridad a la Asamblea General de las Naciones Unidas. Su manifestación normativa era la famosa resolución "Unidos para la Paz" del 2 de enero de 1950.

Durante más de cuarenta años de su actividad, la ONU instituyó las catorce operaciones de paz, de las cuales seis eran con el empleo de las fuerzas armadas y ocho con el aprovechamiento de los observadores militares. Las diferencias entre "las fuerzas" y "los observadores" eran y son tanto en la teoría como en la práctica asaz borrosas. ${ }^{4} \mathrm{~A}$ pesar de que los números de personas involucradas, en promedio, en las operaciones de paz, no reflejan siempre su orden de magnitud, en algunas de ellas participaron bastantes 'cascos azules', como en el Congo durante 1960-1964. En total, por este país africano pasaron casi veinte mil miembros de las fuerzas armadas de la ONU.

A partir de la última década del siglo próximo pasado, las tradicionales acciones de la ONU del mantenimiento de la paz comenzaron a transformarse en las operaciones de su obtención por la fuerza. ${ }^{5}$ En este género de emprendimientos no era suficiente el clásico modus operandi: pacíficas acciones preventivas; instauración de la paz; su mantenimiento. El viraje decisivo en este ámbito lo produjo la operación de paz en el Golfo Pérsico. Con la anuencia del Consejo de Seguridad la paz ha sido impuesta por medio de la fuerza. ${ }^{6}$ El éxito de esta operación era una prueba de que la paz se puede restablecer al echar mano del salvajismo militar. Este nuevo fenómeno no encontró hasta ahora una definición satisfactoria. Algunos autores lo definen como una intervención llevada a cabo por las fuerzas armadas con el objetivo de hacer separar las partes beligerantes.

El estado de complejidad política y militar de los modernos conflictos permite afirmar que la actual operación de paz es una sucesión de las

4 Como dijo un funcionario del Secretariado de la ONU, "no hubo una palabra mejor, de la cual se pudiera servirse". Lo cito siguiendo a Zapalowski, L., Operacje pokojowe ONZ [Las operaciones de paz de la ONU], Cracovia 1989, p. 41.

5 Esta alteración en la naturaleza de las operaciones se reflejó incluso en la modificación de terminología. Es característico aquí el título de la monografía de Snow, D. M., Peace Keeping, Peace Making and Peace Enforcement: The U.S. Role in the International Order, Carlise Barracs, 1993.

6 Compárese Czaplinski, W. y Wyrozumska, A., op. cit., nota 3, pp. 519-421. 
acciones con el empleo de la violencia y con la aplicación de las armas mortíferas. Aún más, la ONU al no estar en condiciones de instaurar por sí mismas la paz, hace autorizar cada vez más a las organizaciones y a las fuerzas regionales. De otra parte, aparecen hasta las propuestas de crear - eficaces desde la óptica castrense - las fuerzas armadas permanentes. ${ }^{7}$

Otra faceta del nuevo papel de las operaciones de paz es su catalogación como una tercera vía entre la acción humanitaria y la intervención militar a secas. En el último decenio de la centuria pasada se abrió paso la concepción de que el respeto a los derechos humanos es tan estrechamente ligado con el mantenimiento de la paz mundial por el Consejo de Seguridad de las Naciones Unidas, que está justificado incluso el uso de las fuerzas armadas. Se trata del denominado método político-humanitario, por medio del cual la ayuda se suministra bajo la protección del ejército.

Aunque el orden jurídico internacional no reconoce el derecho a la injerencia humanitaria, la práctica del Consejo de Seguridad está rica en los ejemplos de este talante. ${ }^{8}$ De este modo, se entregó 'al amparo de las bayonetas' los víveres para los más necesitados de la población civil de Irak y Kuwait, así como para los kurdos en la parte norteña del primer país mencionado. En la Resolución del Consejo de Seguridad de la ONU del 1992, se hace constar que las partes interesadas "emprenderán las medidas indispensables para asegurar la seguridad del personal de las Naciones Unidas y de otras organizaciones involucradas en el suministro de la ayuda humanitaria". La unánimemente aprobada Resolución núm. 794 del Consejo de Seguridad de la ONU sobre Somalia contuvo senci-

7 Compárese el interesante artículo de M. Kowalewski bajo el título significativo "Kryzys i rozwoj operacji pokojowych. Symptomy kryzysu" ["La crisis y el desarrollo de las operaciones de paz. Síntomas de malestar'], aparecido en la revista del Instituto de Asuntos Internacionales adjunto a la Cancillería polaca Sprawy Miêdzynarodowe, 1995, núm. 1, pp. 95-112.

8 La Corte Internacional de Justicia (Tribunal de la Haya), al fallar en el caso nicaragüense hizo notar que para que "una intervención no sea un reprobable entremetimiento en los asuntos internos de otro Estado, no sólo la 'asistencia humanitaria' debiera constreñirse a los fines ratificados por la experiencia de la Cruz Roja, a saber, a la 'prevención y al alivio a los sufrimientos del hombre' y la 'protección de la vida y de la salud', la 'garantía del respeto al ser humano'; también ella debiera ser seguramente suministrada indiscriminadamente a todas las persona en la necesidad", International Court of Justice. Report of Judgements, Advisory Opinions and Orders (en adelante ICP Rep.), 1986, p. 125. En la parte ulterior del veredicto esta instancia comprobó que "El empleo de la fuerza no puede ser un método apropiado del control y del aseguramiento de los derechos humanos", en el mismo lugar, p. 134. 
llamente el beneplácito para la intervención militar con fines humanitarios. $^{9}$

\section{ABSOLUTA DEFENSA DE LOS 'DERECHOS \\ DE LA DIGNIDAD HUMANA' 10}

Los documentos jurídicos que regulan la dignidad humana la formulan siempre de manera absoluta. Basta aquí citar el primer artículo de la Ley Fundamental alemana de 1949 que reza que la dignidad del hombre es inviolable o el idéntico artículo de la Carta de los Derechos de la Unión Europea. Estos enunciados tajantes tienen como su premisa que la dignidad de la persona humana es un fundamento o una fuente de todas sus libertades y derechos.

Sin embargo, no todas las libertades y derechos del individuo resultan directamente de la dignidad del hombre o se conectan con ella, por ejemplo, el derecho al trabajo. De un lado, el trabajo contribuye al desarrollo de la humanidad en el hombre, a su preeminencia. De otro lado, el trabajo puede ser un atentado a la dignidad humana puesto que éste es una coacción. El trabajo acerca, hasta equiparar, al individuo con un animal, con una máquina o con una cosa. Aun cuando el trabajo no puede vulnerar la dignidad del hombre, esta actividad puede deshumanizarlo.

9 W. Czaplinski y A. Wyrozumska describen en su libro arriba citado (p. 502) el fin de la operación humanitaria en Somalia, de esta manera: en 1993 se produjeron sin embargo algunos acontecimientos imprevistos, las tropas de las Naciones Unidas (UNOSOM II) han sido acometidos varias veces, por lo cual perdieron la vida tanto las personas civiles como los soldados de las fuerzas de paz. Los estadounidenses tomaron una acción militar contra las fuerzas del general Aidida, entre otros, un ataque de helicópteros a la sede de su comandancia. El asalto estadounidense ha sido censurado por algunos países, especialmente por Italia, cuyas fuerzas integraron las tropas de la ONU (UNOSOM II). Los EUA solicitaron incluso el reemplazo del comandante del contingente italiano, lo que provocó una protesta de este país. Las disensiones entre los Estados, así como los ataques repetidos contra las fuerzas de la ONU (UNOSOM II) llevaron al final a la toma de la decisión de retirar las tropas del territorio de Somalia y de terminar su mandato.

10 Prescindiendo del neologismo contenido en el subtitulo, haré observar que el absoluto carácter de algunos derechos individuales en el orden jurídico internacional se define como ius cogens. Cuando se mira desde la teoría de los derechos humanos se habla de los llamados derechos intangibles, inderogables, inviolables, etcétera. Estos derechos constituirían el denominado 'núcleo duro' del orden jurídico internacional. Compárense la extensa monografía bilingüe sobre el tema bajo la dirección de Premont, D. et al., Droits intangibles et etats d'exception. Non-derogable rights and states of emergency, Bruselas, Bruylant, 1996. 
No existe algún catálogo o una lista cerrada de los derechos conectados estrechamente con la dignidad humana. No cabe duda que lo mínimo en este ámbito constituyen los preceptos de los convenios internacionales y de las Constituciones políticas de los Estados sobre el derecho a la vida y la interdicción del trato inhumano del individuo. ${ }^{11} \mathrm{El}$ artículo 40 de la vigente ley fundamental polaca, al resumir sintéticamente las disposiciones de estos documentos internacionales, reza que "nadie puede ser sometido a torturas ni a tratos o penas crueles, inhumanos o degradantes. Se prohíben las penas corporales". ${ }^{12}$

\section{Instrumentos del derecho internacional universal}

En el derecho internacional existe un consensus en cuanto a la interdicción arbitraria de la privación de la vida del hombre o de su trato inhumano. ${ }^{13}$ El punto 1 del artículo 6 del Pacto Internacional de Derechos Civiles y Políticos del 19 de diciembre de 1966 reza que "el derecho a la vida es inherente a la persona... Nadie podrá ser privado de la vida arbitrariamente". El punto 2 del mismo artículo dispone que:

11 El autor español de la monografía sobre la dignidad humana escribe que a pesar de que la dignidad está en la base de todas las libertades y derechos del individuo, en algunos de ellos se manifiesta ella especialmente como en el derecho a la vida y en el de su integridad física y síquica. González Pérez, J., La dignidad de la persona, Madrid, 1986. Compárense también Herms, E. (dir.), Menschenbild und Menschenwurde, Gutersloh, 2001; Pavia, M. L. y Revet, T., La dignite de la personne humaine, París, 1999; Bartolomei, F., La dignita umana come concetto e valore costituzionale, Torino, 1987; Kretzmer, D. y Klein, E., The Concept of Human Dignity in Human Rights Discourse, La Haya-London-Nueva York, 2002; Maurer, B., Le principe de respect de la dignite humaine et la Convention europeenne des droits de l'homme, París, 1999.

12 El concepto de las llamadas penas corporales que huele algo viejo puede servir en Polonia de un argumento adicional en favor de la supresión de la pena de muerte como castigo corporal más severo. La enmienda VIII a la Constitución de los EUA - la cual equivale grosso modo al artículo 40 de la carta magna polaca - es el objeto de una aguda controversia entre los partidarios y los oponentes de la pena de muerte. Compárense los trabajos de R. Berger (que se pronuncia a favor de esta medida de represión) y de H. A. Bedau (el cual presenta los argumentos contrarios) en el libro colectivo dirigido por Mayer, M. J. y Parent, W. A., The Constitution of Rights. Human Dignity and American Values, London, Ithaca, 1992.

13 Compárense las conclusiones del simposio de la Asociación Internacional de los expertos en los derechos humanos (CID) contenidas en la obra bilingüe dirigida por Premont, D. y Montanta, Fr., Le droit a la vie. Quarente ans apres l'adoption de la Declaration Universelle des Droits de l'Homme: Evolution conceptuelle, normative et jurisprudenatielle. The Wright to Life. Forty Years after the Adoption of the Universal Declaration of Human Rights: Evolution of the Koncept, Norms and Case-Alw, Ginebra 1992. 
En los países que no hayan abolido la pena capital sólo podrá imponerse la pena de muerte por los más graves delitos y de conformidad con leyes que estén en vigor en el momento de cometerse el delito y que no sean contrarias a las disposiciones del presente pacto ni a la Convención para la prevención y la sanción del delito de genocidio. Esta pena sólo podrá imponerse en cumplimiento de la sentencia definitiva de un tribunal competente". La primera frase del siguiente artículo del pacto estatuye que "nadie será sometido a torturas ni a penas o tratos crueles, inhumanos o degradantes.

A pesar de que el punto 4 del artículo 4 del pacto en cuestión prevé la posibilidad de suspender las obligaciones contraídas en virtud de este pacto "en situaciones excepcionales que pongan en peligro la vida de la nación y cuya existencia haya sido proclamada oficialmente", no se puede hacerlo jamás (punto 2) respecto del derecho a la vida o de la prescripción del trato humano con el hombre. ${ }^{14}$

El llamado artículo 3 común -idéntico en los cuatro Convenios de Ginebra del 12 de agosto de 1949 - prohíbe en caso de un conflicto armado desprovisto del carácter internacional todas las violaciones sobre la vida y las personas, especialmente los homicidios de cualquier clase, mutilaciones, tratos crueles y torturas. El artículo 4 del Protocolo II interdice "para siempre y en todos lugares los atentados contra la vida, la salud o el equilibrio físico o psíquico de las personas, particularmente los homicidios... las penas colectivas, la toma de los rehenes" o en general "una amenaza de cometer cualquiera de los hechos mencionados".

Se veda impartir órdenes que no permitan que alguien pueda seguir vivo. Cuando tal orden fuere dada o cualquier otra que se relaciona con la privación de la vida, las aprobadas en 1991 por la ONU Principios Básicos del Uso de la Fuerza y del Arma de Fuego por los Funcionarios del Orden Público facilitan la extensión del deber del recurso a estas accio-

14 La excepcional importancia de este pacto ha sido percibida ya en 'Polonia bajo el comunismo'. El profesor de derecho constitucional - un exponente ideológico del régimen por antonomasia- escribió que ambos pactos (es decir, también el Pacto Internacional de Derechos Económicos, Sociales y Culturales, aprobado por la Asamblea General de la ONU en la misma fecha del 16 de diciembre de 1966) se caracterizan por el "alto valor jurídico (igual al acuerdo internacional), son las "fuentes del derecho internacional de pleno valor", se les atribuye el "papel conductor, casi constitucional entre otros instrumentos de esta rama del derecho. Sokolewicz, W., "Prawo narodow do samostanowienia" ["El derecho de las naciones a la autodeterminación"], en Instituto de Ciencias Jurídicas de la Academia Polaca de Ciencias, Prawa clzowieka. Model prawny [Los derechos del hombre. Modelo jurídico], Varsovia, 1991, p. 24. 
nes por los integrantes de las fuerzas armadas de esta organización mundial. Este documento manda a los Estados la adopción de las leyes que posibilitan a sus representantes oficiales, específicamente al llamado personal de uniforme, la negativa de cumplir una orden de uso de la fuerza o de las armas de fuego. El principio núm. 26 preceptúa que la sumisión a las órdenes de los superiores no constituye una justificación, si los funcionarios del poder establecido sabían que la orden de uso de la fuerza o de la arma de fuego cuyo resultado es la muerte o la lesión corporal grave del hombre era manifiestamente contraria al derecho y ellos tuvieron posibilidad suficiente de rehusar su cumplimiento. En todo caso, la responsabilidad recae también sobre los superiores que emitieron tales órdenes ilegales.

Los preceptos arriba referidos componen lo que se llama la cláusula Martens, incluida entre otras cosas en el preámbulo de los Convenios de la Haya de 1899 y 1907, que codifican las leyes y costumbres de la guerra. ${ }^{15}$ Según ella (en su formulación actual), "en los casos no previstos en la presente Convención, en sus Protocolos anexos o en otros acuerdos internacionales, la población civil y los combatientes permanecerán, en todo momento, bajo la protección y la autoridad de los principios de derecho internacional derivados de la costumbre, de los principios de humanidad y de los dictados de la conciencia pública". En otras palabras, los beligerantes o, en general, los que se encuentran apenas en la órbita de un conflicto armado no tienen un derecho ilimitado a escoger los medios y métodos de combate.

Según el criterio generalizado de los conocedores del derecho internacional, esta cláusula entraña el llamado mínimo de la humanidad, es decir la dignidad de la persona humana. A los enunciados de la cláusula se les considera como el fundamento entero del derecho internacional humanitario. Esta regla especial del derecho internacional de los conflictos armados manda subordinar todos los intereses de grupo a los principios elementales de la humanidad, o sea sencillamente a la dignidad humana.

15 La versión original de la cláusula incorporada inicialmente en los preámbulos de ambos convenios aludidos, luego en los artículos 63, 62, 142 y 158 de los cuatro convenios de Ginebra de 1949, después en el artículo 1 del Protocolo I y en el preámbulo del Protocolo II de Ginebra de 1977 — ahora se encuentra plasmada en el preámbulo de la Convención de Nueva York de 1980_. 


\section{Jurisprudencia del Tribunal de la Haya}

También en los asuntos ventilados por la Corte Internacional de Justicia se puede advertir la acentuación cada vez mayor de las normas imperativas protectoras de la dignidad del hombre. ${ }^{16}$ Esto es el resultado de la lenta formación de las llamadas reglas ius cogens. En el caso del estrecho de Corfú de 1947, la Corte Internacional de Justicia hizo notar que la obligación internacional de comunicar sobre la existencia de los campos de minas descansa en el VIII Convenio de la Haya de 1907, el cual se aplica durante la guerra, pero sobre la base de las reglas generales universalmente reconocidas, a saber: consideraciones elementales de la humanidad que deben regir todavía más durante un enfrentamiento bélico que en los tiempos de paz. ${ }^{17}$

Un paso más hizo esta instancia en su opinión consultiva del 1951 sobre las reservas a la Convención para la Prevención y la Sanción del Delito de Genocidio. En esta opinión el órgano referido inicio una línea jurisprudencial sobre la existencia de las obligaciones erga omnes en materia de los derechos humanos. En particular, el tribunal declaró que tales principios se hallan en la base de la convención aludida como son los principios reconocidos que "comprometen a los Estados también fuera de todos los lazos convencionales". ${ }^{18}$

En la propedéutica opinión consultiva del 1971, relativa al Caso de Namibia, la Corte Internacional de Justicia puntualizó que la Carta de la Organización de las Naciones Unidas impone a sus miembros las obligaciones legales en el ámbito de los derechos humanos. Según este órgano "el cese del mandato y la comprobación de la ilegalidad de la presencia de la República Sudafricana en Namibia se les puede hacer efectivo respecto a todos los Estados en tal sentido que ellos no excluyen una situación ilegal erga omnes, la cual se mantiene con la violación del derecho internacional". A juzgar por el dictamen de esta corte, el antiguo mandatario se obligó a acatar y a respetar en los territorios con el estatus internacional "los derechos humanos y las libertades fundamentales para con todos, sin reparar en razas". El hecho de establecer e imponer estas distinciones, exclusiones, limitaciones y restricciones, basadas únicamente

16 Compárense la excelente monografía sobre el tema de Gómez Robledo, A., El ius cogens internacional (estudio histórico-crítico), México, UNAM, 1982.

17 ICJ Rep. 1949, p. 22.

18 ICJ Rep. 1951, p. 23. 
sobre la raza, el color de piel, nacimiento o origen nacionales o étnicos es "la negación a la persona humana de los derechos fundamentales". ${ }^{19}$

También, desde la óptica de la protección de los inalterables derechos humanos del individuo, este órgano resolvió el asunto de los rehenes estadounidenses en Teherán. El Tribunal de la Haya hizo notar que el hecho "de la privación infundada de la libertad de los seres humanos, así como su sometimiento en las condiciones penosas al apremio físico es evidentemente no compatible con los principios de la Carta de la ONU y con los derechos fundamentales contenidos en la Declaración Universal de Derechos Humanos".

Aunque la Corte Internacional de Justicia nunca dio una lista de normas incondicionalmente vinculantes del derecho internacional universal, en la decisión del 1070 en el caso Barcelona Traction, expuso su registro aproximado. El fallo preceptúa que se debe hacer una esencial distinción entre las obligaciones de los Estados para con la entera comunidad internacional y las que surgen respecto a un otro Estado en el ámbito de la protección diplomática. Por razón de su naturaleza, las primeras conciernen a todos los Estados. Al tener presente el peso de los derechos de que se trata, todos los Estados pueden ser considerados como los que tienen un interés para que ellos sean tutelados.

De este modo, estos compromisos son "obligaciones erga omnes". En el moderno derecho internacional:

Estas obligaciones resultan por ejemplo de la puesta fuera del derecho los actos de agresión y de genocidio, así como de los principios y de las normas tocantes a los derechos fundamentales de la persona humana, englobando aquí asimismo la protección contra la esclavitud y la discriminación racial - ciertos derechos y la protección que les corresponde esta incluida en el derecho de gentes universal... otras resultan de los documentos internacionales de alcance mundial o casi mundial_. ${ }^{20}$

La evolución de la jurisprudencia de la Corte Internacional de Justicia confirma la creciente vinculación por las normas imperativas del derecho de gentes universal. Cada vez más su tenor está determinado por los derechos humanos. A pesar de la resistencia de ciertos países en contra de este talante de normas, su plena aceptación internacional no es un

19 ICP Rep. 1971, pp. 56 y 57.

20 ICJ Rep., p. 32. 
objetivo lejano. ${ }^{21} \mathrm{El}$ irresistible avance de la norma ius cogens no será detenido. ${ }^{22}$ La tutela de los derechos humanos dejó de ser - a finales del milenio pasado - sólo un asunto interno de los Estados. El proyecto de artículos relativos a la responsabilidad de los Estados, confeccionado por la Comisión de Derecho Internacional de la ONU definió la "vulneración grave - en amplia escala — de la obligación internacional de importancia básica para la protección de la persona humana" como "un crimen internacional". ${ }^{23}$

\section{CIRCUNSTANCIAS EXIMENTES DE LOS ORDENAMIENTOS JURÍDICOS INTERNOS}

Las antes expuestas prohibiciones por el derecho internacional de determinadas conductas - homicidios, torturas, etcétera- son desprovistas de la sanción y no indican un órgano capaz de llamar a la responsabilidad en caso de su vulneración. Al tener la figura de las interdicciones absolutas tampoco prevén las causas que eximen su antijuridicidad.

Semejantes prohibiciones, a veces idénticas, hay en los sistemas jurídicos nacionales. Ellos prevén determinadas penas por su comisión y señalan la índole del órgano que las impone. El derecho criminal de estos países establece también estas mismas causas que exoneran la responsabilidad o al menos la suavizan cuando ocurre la vulneración de los derechos de la dignidad humana: asesinato, mutilación, etcétera. A continuación, examinaremos dos circunstancias eximentes más conocidas y empleadas: la legítima defensa y la obediencia militar.

No anula esta contradicción la instauración del Permanente Tribunal Penal Internacional (PTPI), que entró en funcionamiento el 1o. de julio de 2002. Este órgano está destinado a juzgar los crímenes más graves contra el derecho internacional (genocidio, crímenes de lesa humanidad,

21 Basta recordar aquí la postura negativa de Francia respecto al artículo 53 de la Convención de Viena del Derecho de Tratados para con la Normas Ius Cogens o la de EUA respecto a la creación del Tribunal Penal Internacional.

22 Compárese el punto IC en: Rapport de la Reunion d'experts sur les droits non susceptibles de derogation dans les etat sou situations d'exceptio. Report of the Metting of Experts on Rights not Subject to Derogation During Staates of Emergencje and Exceptional Circumstances. Este documento puede leerse en Goralczyk, W., Prawo miêdzynarodowe publiczne wzarysie [Compendio de derecho internacional público], Varsovia, 2000. Se trata de una edición corregida y ampliada de este popular manual por S. Sawicki.

23 Según Czaplinski W. y Wyrozumska, A., op. cit., nota 3, p. 500. 
crímenes de guerra, agresión), entre los cuales no hay los individuales hechos punibles no calificados, en pequeña escala, sin el gran número de muertos, torturados, etcétera. Como escribió un participante polaco en la Conferencia de Roma que estableció el PTPI, la represión de los soldados de las fuerzas de paz culpables de "algunas violaciones del derecho... se podría incluir a la jurisdicción del Tribunal sólo con la máxima mala voluntad". ${ }^{24}$ El Estatuto de Roma presenta, en cambio, una lista completa de circunstancias eximentes. ${ }^{25}$

\section{Legítima defensa}

De la peculiaridad de las operaciones de paz debe resultar su carácter defensivo y conciliatorio conducente, por lo menos, a la tregua entre los beligerantes. El artículo 2 de la Carta de las Naciones Unidas prescribe no sólo la renuncia al uso de la fuerza, sino que también a su amenaza. La interdicción absoluta resulta también del punto 3 de este artículo que reza que los miembros de esta organización resolverán sus litigios a través de los medios pacíficos de tal manera para que no se pongan en peligro la paz internacional, la seguridad y la justicia. Al personal militar usado durante estas operaciones se prohíbe totalmente el uso de las armas. En el curso de las operaciones de paz rige el estricto principio de la presencia, no de la actividad militar. La sola estancia física de los soldados cascos azules y el respeto a la organización mundial deben ser suficientes para el mantenimiento de la paz. ${ }^{26}$

Conforme al artículo 25 del Código Penal polaco, no comete el delito quien obrando en legítima defensa repela un atentado directo, antijurídico contra cualquier bien tutelado por el derecho. Aun cuando se pro-

24 Plachta, M., "Statut Stalego Miedzynarodowego Trybunalu Karnego: podstawowe zasady kompetencyjne, organizacyjne i procesote" ["El Estatuto de la Permanente Corte Penal Internacional: principios básicos competencia, de organización y procedimiento"], Panstwo i Prawo, 1998, núm. 12, p. 35.

25 Compárense los artículos 30-32 del Estatuto de Roma del 17 de julio de 1998. Aquí sólo se puede consignar un cierto progreso en cuanto a la orden del superior. No exonera ningún mandamiento (militar o proveniente de las autoridades civiles y/o gubernamentales) cuando se trata del genocidio y de los crímenes de lesa humanidad. Sin embargo, se puede aducir una circunstancia eximente respecto a los crímenes de guerra o a la agresión.

26 Kowalewski, M., op. cit., nota 7, p. 100, así como el enjundioso artículo de Ocieczek, B., "Ocena skutecznoœci operacji pokojowej ONZ wbylej Jugoslawii" ["La evaluacion de la eficacia de la operación de paz en la antigua Yugoslavia”], Ruch Prawniczy, Ekonomiczny $i$ Socjologiczny, 1998, núms. 3-4, en el cual se tasa específicamente las diferentes medidas de índole no castrense en la Yugoslavia, pp. 136 y ss. 
duzca un exceso en la legítima defensa - es decir cuando su autor echó mano de un modo no proporcional a la peligrosidad - el tribunal puede aplicar la conmutación extraordinaria de la pena, hasta renunciar a su imposición. La corte desiste a infligir el castigo si el exceso en la legítima defensa ha sido el resultado del miedo o de la excitación, justificados por las circunstancias del atentado.

En la teoría del derecho criminal se habla por lo general de las tres condiciones que eximen la antijuridicidad por razón de la legítima defensa. El atentado debe ser real, directo e ilícito. Estas premisas no son - debido a una situación casi permanente de beligerancia en la cual actúan las fuerzas de paz - limitaciones, sino muy al contrario, facilidades para liberarse de la responsabilidad penal. Para las tropas de la ONU, que se encuentran ex defintione entre las partes del conflicto, es difícil considerar los atentados como algo imaginario fuera de lo real. Siempre son directos puesto que - tal como lo plantea la doctrina - crean un peligro durante el cual se está emprendiendo una acción de defensa. Tampoco es difícil privar a estos atentados la cualidad de ilicitud.

La regulación polaca facilita adicionalmente la posibilidad de eludir la responsabilidad a título de la defensa legítima. A diferencia del derecho vigente en otras naciones, el artículo 25, párr. 1o. de nuestro Código Penal no introduce restricciones en cuanto a la índole del bien objeto del ataque que da pábulo a la defensa legítima. En relación con esto, éste puede ser no sólo — como por ejemplo en el derecho criminal austriaco - la vida, la salud, la integridad corporal, la libertad y las propiedades, sino también, entre otras cosas, el honor, la buena reputación de la institución (en este caso de la ONU). ${ }^{27}$ La mayoría de los países de nuestro continente hace depender la legalidad del rechazo del atentado de una cierta proporcionalidad de los bienes. En la normativa criminal polaca falta una explícita y formulada exigencia de la conmensurabilidad entre el bien amenazado y el bien del asaltante puesto en peligro por las acciones de defensa. ${ }^{28}$

La línea jurisprudencial de la Suprema Corte de Justicia polaca es también muy ventajosa para las personas que exceden los límites de la legítima defensa. Según este órgano, la acción en legítima defensa no

27 Compárense Buchala K. y Zoll, A., Kodeks karny. Czesc ogolna. Komentarz do art. 1-116 Kodeksu karnego [El código criminal. Parte general. Comentario a los arts. 1-116 del Código criminal], Cracovia, Zakamycze, 1998, p. 219.

28 En el mismo lugar, pp. 224 passim. 
pierde su carácter legal debido al hecho de que el asaltante no ha sido previamente llamado para que cese el ataque o advertido de que se vaya a emplear un medio indispensable para parar la acometida en caso de continuarla. ${ }^{29}$ En adición a esto, la máxima autoridad judicial patria se pronunció de manera unívoca a favor del carácter autónomo de la legítima defensa. Esto quiere decir que la condición para admitir una repulsa del ataque a costo del bien del asaltante, no es la posibilidad de huir de la amenaza por el afectado en contra de su bien, sino sólo mediante el sacrificio del bien del asaltante. El atacado tiene el derecho de repeler el ataque a costo del bien del asaltante aun cuando existe una posibilidad real de evitar la amenaza del bien arremetido de otra forma, por ejemplo, al fugarse, al apartarse, al hacer un disparo de advertencia. ${ }^{30}$

Si miramos las tres condiciones del ejercicio de la legítima defensa desde el punto de vista de su práctica judicial polaca, su entendimiento en la jurisprudencia es todavía más liberal que suponían las recomendaciones teóricas en este terreno. Basta recordar dos fallos controvertibles de nuestros tribunales de derecho común: la eliminación total de la responsabilidad de una persona ajena al caso que hizo un disparo al ladrón del aparato de radio de automóvil o la exclusión judicial de la compensación por el dueño de la casa a los ladrones cuando ya se retiraban del lugar.

\section{Obediencia militar}

Todavía más infringen la dignidad de la persona humana las leyes criminales nacionales reguladoras de la orden militar, específicamente su cumplimiento y la negativa. ${ }^{31}$ Por ejemplo, el artículo 318 del actual Có-

29 En el mismo lugar, compárense también el fallo de la Suprema Corte de Justicia del 2 de febrero de 1979, en el cual este órgano expuso su opinión que el que rechaza el ataque no está obligado a informar el asaltante que se vaya a defender. Rejman, G. (dir.), Kodeks karny. Czêsae ogolna. Komentarz [El código criminal. Parte general. Comentario], Varsovia, 1999, pp. 705 y 706.

30 Compárense Buchala, K. y Zoll, A., op. cit., nota 27, pp. 222 y 223, así como Rejman, G., op. cit., nota anterior, pp. 705 y 706.

31 Esta cuestión se presenta peor en el vigente Reglamento General de las Fuerzas Armadas de la República de Polonia. Su punto 26 dispone que "en los casos justificados el subordinado puede pedir la orden escrita... El que ordena tiene el deber cumplir con tal solicitud y el subordinado está obligado de ejecutar tal orden". El punto 27 del Reglamento reza que "Si el soldado reciba el orden... cuya ejecución sería contraria a las normas a las que está supeditado, da parte sobre esto al que dio la orden. En caso de confirmación de esta orden (contraria a las normas) lo ejecuta". Muy raro es el punto 30 del reglamento que manda que un soldado que es conciente o acepta que está cometiendo un delito asuma la responsabilidad penal; la responsabilidad penal asume también quien 
digo Penal de la República de Polonia reza que "no comete un delito el soldado que realiza un hecho prohibido que es al propio tiempo una ejecución de la orden", mientras que su artículo 334 dice que "no comete el delito de no cumplimiento de la orden el soldado que niega la realización de la orden que entraña la infracción o el cual no la ejecuta". Ambos preceptos - al ser complementarios mutuamente - constituyen la posibilidad de liberarse de la responsabilidad penal por razón de la disciplina militar.

Esto se adecua a la distinción en la teoría del derecho criminal entre la orden antijurídica (artículo 318 del Código criminal) y el delito (artículo 334 del Código criminal). La noción de una orden criminal es más ancho y significa cualquier orden contrario al vigente ordenamiento legal. La orden criminal equivale únicamente a la trasgresión de las normas del derecho penal. En otras palabras, una orden contraria a los preceptos militares del derecho administrativo, civil, internacional, etcétera, no al Código criminal — como escribe M. Flemming - "debe ser ejecutado conforme a las exigencias de la disciplina militar y la responsabilidad por todo esto recae sobre el que dio la orden". ${ }^{32}$

Esto quiere decir que el cumplimiento que infringe las normas internacionales del derecho internacional — que es apenas un acto ilícitoexcluye de manera automática la punibilidad del soldado. La base de tal exoneración es el hecho de que el militar actúa dentro de un error concerniente a las circunstancias que constituyen el cuerpo del delito. En otras palabras, en las condiciones del servicio militar no se puede exigir del soldado considerar las consecuencias de la orden recibida. No es una opinión correcta, puesto que los soldados de las fuerzas armadas de paz están sometidos al curso de formación en materia de las vigentes normas internacionales, incluido el derecho humanitario de los conflictos arma-

dio tal orden. Esta afirmación es válida independientemente de los puntos 26 y 27, cuyo tenor hay que entender como una acción en los límites del derecho ( $\mathrm{sic}$ ). Al prescindir del carácter jurídico del Reglamento General de Las Fuerzas Armadas de La República de Polonia - puesto en vigor por medio de la decisión del ministro de Defensa Nacional del 5 de julio de 1994 y las contradicciones internas aludidas, uno puede meditar sobre el sentido de la sofisticada construcción de los preceptos del Código criminal relativos a la orden, ignorados por completo en la decisión ministerial-. Resulta superfluo recalcar que los soldados de las unidades militares polacas que llevan a cabo las tareas fuera de las fronteras patrias están subordinados en materia de la disciplina castrense exclusivamente a los superiores militares polacos. Compárese Fleming, M., Kodeks karny czesc wojskowa. Komentarz [Código criminal parte militar. Comentario], Varsovia, 2000, p. 49.

32 Ibidem, p. 51. 
dos. Existe pues una presunción fuerte de que el soldado que lleva a la práctica la orden que satisface a un hecho constitutivo de delito sabe lo que está haciendo.33

En lo que atañe a una orden criminal prevista en el artículo 334 del Código criminal polaco, el soldado puede resistirlo sin asumir responsabilidad alguna por haber cometido un acto de insubordinación. Más aún, cuando la insubordinación la hizo con el fin de disminuir sustancialmente la peligrosidad del hecho, puede esperar la conmutación excepcional de la pena hasta la renuncia a su imposición. Toda esta lógica no puede aplicarse en ningún momento a las violaciones del derecho internacional, puesto que a tono con el Código criminal polaco no se les considera como delitos. En otras palabras, dicha causa eximente es sólo buena para liberarse de la responsabilidad que se fundamenta en el Código criminal cuando un soldado insubordinado sea al propio tiempo acusado de su vulneración.

En ambos casos, el punto de partida de la distinción entre los diversos géneros de los hechos eran las normas legales. En la problemática investigada se trata de los hechos definidos en las normas internacionales. De acuerdo con las normativas estudiadas, éstas son indiferentes para el orden jurídico polaco, especialmente para el penal. Esta regulación requiere una meditación sobre el lugar de los acuerdos internacionales en el sistema jurídico polaco. Conforme al artículo 98 de la Constitución, la inclusión al ordenamiento normativo polaco de un convenio internacional relativo a las libertades, derechos y deberes ciudadanos, exige un previo consentimiento expresado en la ley. No cabe duda que este tipo de acuerdos son los convenios internacionales humanitarios.

Según el artículo 91 al. 1 un acuerdo internacional ratificado por medio de este procedimiento tiene la prelación ante una ley, si esta ley se puede compaginar con el acuerdo. En otras palabras, las interdicciones absolutas de la violación de los derechos de la dignidad humana deben regir también en el orden jurídico nacional. Además, ellas deben tener la

33 Compárese el interesante artículo periodístico bajo el título significativo de Lentowicz, Z., "Psycholog idzie na wojnê" ["El psicólogo va para la guerra"], Rzeczpospolita, del 7 de diciembre de 2000. Sin embargo, la doctrina militar polaca no ve, hasta ahora, problemas algunos en este ámbito. Chytrowski, W., "Ochrona ludzkiej godnoœci podczas konfliktu zbrojnego i stanow nadzwyczajnych" ["La protección de la dignidad humana durante el conflicto armado y los estados de emergencia"], en Jasudowicz, T. (dir.), Miedzynarodowe prawo humanitarne [El derecho internacional humanitario], Torun, 1997, pp. 13-42. 
primacía respecto a todas las normas contrarias del derecho interno estatal. Si es así, no se hubiere podido aplicar a ellas la regulación referida a las circunstancias eximentes del derecho penal.

\section{CONCLUSIONES}

El examen de la regulación jurídica de las llamadas "operaciones de paz" lleva a la conclusión de que ésta no se ajusta a la nueva etapa de la tutela de los derechos humanos, cuyo punto de partida es la dignidad de la persona. Esta categoría no interiorizada, o incluso menospreciada por los juristas de corte positivista, tiene o tendrá un gran papel a desempeñar en la evolución ulterior del derecho. Desde ya, la dignidad humana está en la brega contra el denominado progreso técnico-científico de la civilización. En este sentido, basta recordar el avance de la genética o de la informática.

En la época de la expansión de los movimientos pacifistas, despiertan reservas cada vez más grandes las acciones internacionales encaminadas a imponer la paz, es decir, en el cumplimiento de una encomiable idea de hace más de medio siglo. Las operaciones de la predecesora de la ONU (la Liga de las Naciones) se cubrieron con la vergüenza, mientras que las actuales se deshonran gradualmente. Me doy perfecta cuenta de que estas palabras tajantes no serán del agrado de muchos partidarios de las modernas "cruzadas"; sin embargo, creo que cuanto más temprano se detengan estas "expediciones castrenses humanitarias", ganará más la legalidad internacional.

Se puede poner en tela de juicio esta conclusión al decir que las sociedades tienen que defenderse contra las violaciones de los derechos humanos, especialmente de la dignidad de la persona. Sin embargo, no se puede decir que la mejor manera de defensa de la tranquilidad mundial es el consentimiento a las vulneraciones de la dignidad humana. En la vida social se comenten diferentes crímenes. La respuesta a éstos no puede ser la represión de escogidos grupos o de individuos que comenten virtualmente o en la realidad estos quebrantamientos del derecho. El género humano hace mucho tiempo que eliminó de su arsenal de medidas de corrección la responsabilidad colectiva. El hombre como un valor supremo, como un fin "en sí mismo" o una "santidad", ha sido puesto en el centro de la concepción moderna de los derechos humanos. 
A tono con este enfoque, resulta que no se puede sacrificar ni una sola persona humana para salvar una mayoría, o menos aún algunos intereses superiores o vitales. Esto sería una nueva vuelta a las teorías que proclaman que la única cosa por la cual vale luchar es un grupo, una comunidad, una nación, una raza, etcétera. Actualmente, un individuo es la medida de todas las cosas. Uno puede no conformarse con esta manifestación soberbia del sofista Pitágoras. No obstante, conviene admitir que esta postura en favor de la dignidad humana es ya visible en la jurisprudencia o al menos como un puntal fuerte en el programa del desarrollo de los derechos individuales en el iniciado tercer milenio.

En la actualidad es difícil imaginarse un cambio en los preceptos del derecho internacional y/o interno estatal en el sentido de renunciar por completo a cualquier posibilidad o circunstancia legales conducentes a la privación de la vida humana o a la aplicación a las personas de procedimientos humillantes. Sin embargo, las prohibiciones existentes en este ámbito se oponen cada vez más a las exculpatorias normas jurídicas arraigadas en los sistemas de derecho nacionales, tales como la defensa legítima o el orden militar. En la hora de ensanchar el derecho a la defensa judicial, o en general de la creciente vigilancia sobre los actos de poder público, se puede esperar que llegará pronto el tiempo de restringir también estas excusas absolutorias por antonomasia.

El principio del control civil sobre el ejército tendrá un gran papel a cumplir en este terreno. A la cambiante función del ejército en los ordenamientos jurídicos nacionales debe corresponder también su reducción en la palestra internacional. Si no ocurriera eso, se verán, como lo vaticina el general Wesley Clark (comandante en jefe de las tropas de la OTAN durante el primer conflicto militar de esta alianza) batallas cada vez más complejas, durante las cuales "a pesar de la desgana a los riesgos y a las víctimas, la mayoría de los Estados occidentales será políticamente... capaz a emprender las intensivas acciones de guerra altamente destructivas... con el uso de todo tipo de armas". ${ }^{34}$

Estas aseveraciones pueden ser referidas no sólo al ordenamiento jurídico polaco, sino a la mayoría de los ordenamientos jurídicos nacionales. En este orden de ideas, se requiere un cambio radical para con los convenios internacionales. Se debe abandonar la tesis generalmente man-

34 Clark, W., "Bitwy coraz bardziej zlozone" ["Las batallas cada vez más complejas"], Rzeczpospolita, 7 de diciembre de 2000. 
tenida de que el derecho internacional es sólo una de las fuentes del derecho nacional y bajo la condición de que en su contenido haya preceptos de índole normativa, aptos para su aplicación inmediata. ${ }^{35}$ Las normas jurídicas acabadas, esto es, pertrechadas de todos los componentes imprescindibles, no son frecuentes en el derecho internacional.

En este orden de ideas, es difícil hablar de la denominada aplicación directa del derecho criminal internacional en los sistemas jurídicos nacionales, especialmente en los foros judiciales. Sigue persistiendo la prudente actitud de que el derecho internacional se limita a formular los compromisos sólo para los Estados partes, con el fin de que éstos configuren en modo determinado su legislación; por ejemplo, al introducir como tipos delictivos la falsificación de la moneda extranjera o los preparativos para la venta de las drogas, los cuales no son por lo general reprimidos internamente dentro de los países individuales. ${ }^{36}$

Sin embargo, las normas imperativas de derecho internacional general no dependen de la voluntad de los Estados particulares (contrástese el artículo 53 de la Convención de Viena sobre el derecho de los tratados, del 23 de mayo de 1969). Ellas son sencillamente ius cogens. Y si es así, no es fácil presentar las propuestas de lege ferenda sobre las normas en vigor. A pesar de todo, las insinuaciones en este sentido se las presentaron ya en un país de nuestro continente. ${ }^{37}$ Será interesante seguir la evolución de esta cuestión en Polonia y en otros países que se hallan en el mismo o parecido estado normativo de la cuestión, en el umbral del tercer milenio.

35 Compárese Marek, A., Komentarz do kodeksu karnego. Czesc ogolna [Comentario al Código criminal. Parte general], Varsovia, 1999, p. 4.

36 Tal es, al menos en Polonia, los ejemplos aducidos, cito del libro del actual presidente de la Suprema Corte de Justicia, Gardocki, L., Prawo karne [El derecho penal], Varsovia, 2000, p. 31.

37 Cuando en 1986 la Comisión belga encargada de la revisión del Código criminal se pronunció casi unánimemente (con excepción de un solo voto, pero con el apoyo de la mayoría de las facultades de derecho del país) en favor de la introducción en este de la disposición relativa a la índole incondicional de las interdicciones internacionales aquí estudiadas. Un cierto número de especialistas y algunos centros de investigación expresaron su inconformidad para con el mismo concepto de prohibiciones absolutas. Compárese Helmons, S. Marcus (dir.), Dignite humaine et hierarchie des valeurs: les limites irreductibles, Academia, 1999, pp. 125 y 126. 